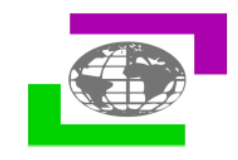

\title{
ANTIDIABETIC EVALUATION OF ISOLATED COMPOUNDS FROM TINOSPORA CORDIFOLIA IN ALLOXON INDUCED DIABETIC RAT MODEL
}

\section{Ram Bindurani L G P*, Singh Anoop}

Faculty of Pharmacy, Bhagwant University, Ajmer, Rajasthan, India.

Article Info: Received 22 November 2019; Accepted 27 December. 2019

DOI: https://doi.org/10.32553/jbpr.v8i6.695

Corresponding Author: Ram Bindurani L G P

Conflict of interest statement: No conflict of interest

ABSTRACT:

Natural products with medicinal value are gradually gaining importance in clinical research due to their well-known property of no side effects as compared to synthetic drugs. Tinospora cordifolia commonly named as "Guduchi" is known for its immense application in the treatment of various diseases in the traditional Ayurveda literature. The present study was aimed to evaluate the anti-diabetic activity of isolated compounds from aerial parts of Tinospora cordifolia (Guduchi) in alloxan induced diabetic rats. Diabetic wistar albino rats were treated with standard drug Glibenclamide and prepared drug formulation in two different doses $250 \mathrm{mg}$ and $500 \mathrm{mg} / \mathrm{kg}$. Hypoglycemic effect was evaluated in these rats and the efficacy of isolated compounds was administered in alloxan induced diabetic rats. At the end of study period blood glucose level were statistically analyzed based on the results. Isolated compounds produced a significant reduction in blood glucose level when compared with non-treated diabetic rats. So the present research work was confirmed that the isolated compounds possess hypoglycemic effect significantly.

Keywords: Tinospora cordifolia, antidiabetic, allaxon induced, Diabetes mellitus.

\section{Introduction:}

Medicinal plant knowledge has usually resulted from trial and error, and was based on speculation and superstition. Medicinal plants remain the prime source of primary health care throughout the world for thousands of years. However, in the middle of 20th century, the contribution of medicinal plants was reduced by approximately one fourth as researchers favored the use of synthetic chemicals for curing diseases. Now this trend is reversing in favor of medicinal plants as they contain natural products that are chemically balanced, effective and least injurious with none or much reduced side effects as compared to synthetic chemicals. ${ }^{1}$ Herbal medicine is thus experiencing a revival in Western society, along with other complementary therapies such as traditional Chinese medicine, Unani, Homeopathy.etc. Diabetes mellitus is well known clinical entity with various late complications like retinopathy, neuropathy, nephropathy, etc. Natural products are known to play an important role in pharmaceutical biology ${ }^{6,7}$. Specific plant knowledge may provide insight for strategic consumption and sustainable use. The alternate medicine system is now gaining momentum with the knowledge of active principles identified from plant species ${ }^{8}$. Karela, Jamun, fenugreek has significant antidiabetic as well as hypolipidemic activity so that it can be used as an adjuvant along with allopathic treatment of medicine to treat diabetes as well as to delay the late complications of diabetes. In the present work, we have elucidated the possible antidiabetic activity of Tinospora cordifoloa and its medicinal potency responsible for the hypoglycemic activity. ${ }^{9,10}$

\section{MATERIAL AND METHODS}

\section{Plant material}

Plant was collected from the India nearby region of Pune during the months of August and September and specimen deposited for taxonomic and ethno medicinal identification to Director, Botanical survey of India, Pune, Maharashtra. Fresh matured aerial parts of Tinospora cordifolia was collected in bulk, initially rinsed thoroughly with distilled water, 
shade dried for 15 days. The shade dried materials were coarsely powder by a mechanical grinder and preserved in a nylon bag in a deep freezer, till further use.

\section{Preparation of extracts}

The plant materials $(1 \mathrm{~kg})$ were initially defatted with petroleum ether and then extracted with alcohol using a Soxhlet apparatus. The yield of the plant extracts ethanol (95\%) measured about $20 \mathrm{~g}$ each after evaporating the solvent using water bath. The standard extracts obtained from Tinospora cordifolia was then stored in a refrigerator at $4^{\circ} \mathrm{C}$ for further use for phytochemical investigation and pharmacological screening.

\section{Preparation of fractions of crude extract}

Ethanolic extract then fractionated using Petroleum ether and Chloroform The ethanolic extract, chloroform fractions obtained from Tinospora cordifolia was then stored in a refrigerator at $4^{\circ} \mathrm{C}$ for further use for phytochemical investigation and pharmacological screening. Petroleum ether fraction was not used in the study because of very less yield.

\section{Animals}

Healthy adult Male albino Wistar rats, weighing 150-200 g were used for the Screening methods.

\section{Investigational model for induction of diabetes}

Diabetes was induced by intra-peritoneal injection of Alloxan monohydrate $(150 \mathrm{mg} / \mathrm{kg}$ b.w.) dissolved in the in normal saline .Blood was withdrawn (0.1 $\mathrm{ml}$ ) from the tip of the tail of each rat under mild ether anaesthesia ${ }^{2}$. The blood glucose level was checked before alloxanisation and after alloxanisation regularly in $24 \mathrm{~h}$ intervals. Animals were considered diabetic when the blood glucose level was raised beyond $200 \mathrm{mg} / 100 \mathrm{ml}$ of blood. This condition was observed at the end of $72 \mathrm{~h}$ after alloxanisation.

\section{Preparation of Interventions}

The measured quantity of extracts and fractions of Tinospora cordifolia and the standard drug glibenclamide (5 mg/kg) was suspended in $25 \%$ Tween-20 in distilled water. The solvent, test samples and standard drugs were administered by oral route based on dose and corresponding weight of the animals. For oral administration of test, standard as well as Solvent Feeding needle no 21 was used ${ }^{3}$.

\section{Maintenance of animals and Exposure Conditions}

Earlier to the experiments, the selected animals were housed in acrylic cages in standard environmental conditions (temp: $20-25^{\circ} \mathrm{C}$; relative humidity: 45-55 \% under $12 \mathrm{hr}$ light/dark cycle), feed with standard rat feed for 1 week in order to adapt to the laboratory conditions and water ad libitum. They were fasted overnight ( $12 \mathrm{hr}$.) before experiments, but were allowed free access to water. Six animals were used for each group of study $^{4}$. All the experiments on animals were conducted in accordance with the internationally accepted principles for laboratory animal use and as per the experimental protocols duly approved by the Institutional Animal Ethical Committee (IAEC/CPCSEA/INV/919/2019), Siddhant college of Pharmacy, Sudumbare, Pune.

\section{Blood glucose level determination}

Fasting blood glucose concentration was determined using a Glucometer (Optimum), based on the glucose oxidase method. Blood samples were collected from the tip of tail at the defined time patterns.

\section{Hypoglycemic activity study of isolated compound on normoglycaemic animals}

\section{(Single dose treated)}

The hypoglycemic activity is important in the diagnosis of diabetes mellitus. It determines the ability of drug to decrease blood glucose level. This method permits for the effect of the drug to be tested in the animal with a whole pancreatic activity. The contrast may give some information regarding mechanism of action. The animals were fasted for $18 \mathrm{~h}$, but were allowed free access to water before and throughout the duration of the experiment. At the end of the fasting period, taken as zero time $(0 \mathrm{~h})$, blood was withdrawn $(0.1 \mathrm{ml})$ from the tip of the tail of each rat under mild ether anesthesia. Plasma was separated following centrifugation the glucose was estimated by the GOD/POD method using a glucose estimation kit from M/s. Sigma Diagnostics (India) Pvt. Ltd., 
Baroda, India. The normal rats were then divided into six groups of six animals each. Group I served as solvent control and received only vehicle (2 $\mathrm{ml} / \mathrm{kg}$ ) through the oral route, Group II received glibenclamide $(5 \mathrm{mg} / \mathrm{kg})$ and served as reference control. Groups III to VI received the compound A and $\mathrm{B}$ of Tinospora cordifolia at a dose of 250 and $500 \mathrm{mg} / \mathrm{kg}$, respectively, through the oral route. Blood glucose levels were examined after 1, 2, 4, 6, 8 and $10 \mathrm{~h}$ of administration of a single dose of the test and control samples.

Antihyperglycemic activity of isolated compound in glucose-loaded animals (oral glucose tolerance test)

The oral glucose tolerance test (OGTT) measures the body's ability to use main source of energy i.e. glucose. OGTT is to simplify and facilitate the diagnosis of diabetes this method is frequently referred to as physiological induction of diabetes mellitus because the blood glucose level of the animal is fleetingly increased with no damage to the pancreas. An oral glucose tolerance test (OGTT) was performed on diabetic rats by feeding glucose $(5 \mathrm{~g} / \mathrm{kg})$ per os. Animals were deprived of food $18 \mathrm{~h}$ before and during the experiment, but were allowed free access to water. They were divided into 7 groups of 6 rats each. Group I served as normal control, Group II served as solvent control and received only vehicle (Tween + water $-2 \mathrm{ml} / \mathrm{kg}$ b.w.) through the oral route. Group III received glibenclamide (5 mg/kg b.w.). Groups IV to VII received the compound $\mathrm{A}$ and $\mathrm{B}$ of Tinospora cordifolia at a dose of 250 and $500 \mathrm{mg} / \mathrm{kg}$ b.w., respectively, through oral route. The blood glucose level was determined before drug and glucose administration ( 1 and $0 \mathrm{~h}$, respectively) and subsequently at $0.5,1,2$ and $3 \mathrm{~h}$ after.

\section{RESULT AND DISCUSSION}

Effect of Isolated compounds of Tinospora cordifolia on Blood Glucose Level of normoglycaemic rats (hypoglycemic activity)

The effect of isolated compounds of Tinospora cordifolia on fasting blood glucose levels of normal rats are presented in table 1 . The plant extracts at both the dose level of 250 and $500 \mathrm{mg} / \mathrm{kg}$ registered 77.42 to $85.32 \mathrm{mg} / \mathrm{dl}$ of fasting blood glucose level at the end of $10 \mathrm{~h}$ of the study, while the standard drug, glibenclamide showed 71.63 $\mathrm{mg} / \mathrm{dl}$ at the same time, with a low degree of significance while compared with solvent treated group. The percentage change of blood glucose of test extracts treated groups at the end of $10 \mathrm{~h}$ showed 4.27 to $15.10 \%$ fall when compared with initial BGL in a dose dependent manner. The potency order of the test extracts towards the falling of BGL is followed by ethanolic extract and chloroform fraction.

Effect of Isolated compounds of Tinospora cordifolia on BGL of glucose loaded hyperglycemic rats (oral glucose tolerance test, OGTT)

The blood glucose level (BGL) of isolated compounds of Tinospora cordifolia glibenclamide and vehicle treated albino rats after oral administration of glucose $(5 \mathrm{~g} / \mathrm{kg})$ are summarized in Table 2 The compound A and B at $250 \mathrm{mg} / \mathrm{kg}$ dose level registered $89.13,92.50 \mathrm{mg} / \mathrm{dl}$ at the end of $3 \mathrm{~h}$ of the study, while it was $91.50,94.51 \mathrm{mg} / \mathrm{dl}$ with dose level of $500 \mathrm{mg} / \mathrm{kg}$. However at the same time the standard drug glibenclamide at $5 \mathrm{mg} / \mathrm{kg}$ showed $62.51 \mathrm{mg} / \mathrm{dl}$ of BGL. However the calculated percentage fall of BGL demonstrated $9.28,20.83$ and $15.73,25.89 \%$ with respect to 250 and $500 \mathrm{mg} / \mathrm{kg}$ dose levels when measured the end of the $3 \mathrm{~h}$ of the study, while at the same time glibenclamide showed a $34.54 \%$ fall of BGL. The progressive fall of $B G L$ of the test extracts, in the different test hour showed a statistical significant of $p<0.05$ to $p<0.01$, while analyzed by using ANOVA followed by Dunnett's t-test. The aqueous extract possesses more BG lowering potency than that of the ethanol extract in a dose dependent manner. The test extracts at tested dose levels also showed a significant fall of BGL while compared with the solvent control group during the study period of 30, 60 and $120 \mathrm{~min}$. 
Table 1: Effect of Isolated compounds of Tinospora cordifolia on Blood Glucose Level of normoglycaemic rats (hypoglycemic activity)

\begin{tabular}{|c|c|c|c|c|c|c|c|c|c|}
\hline \multirow[t]{2}{*}{ Groups } & \multirow[t]{2}{*}{ Treatment and Dose } & \multicolumn{8}{|c|}{ Blood glucose level (mg/dl) } \\
\hline & & 0 & 1 & 2 & 4 & 6 & 8 & 10 & $\%$ decrease at $10^{\text {th }} \mathrm{hr}$ \\
\hline 1 & Diabetic control (tween+ water) & $94.6 \pm 1.1$ & $87.2 \pm 4.62$ & $91.43 \pm 1.86$ & $89.56 \pm 0.81$ & $91.58 \pm 2.23$ & $89.66 \pm 0.46$ & $92.67 \pm 3.22$ & -- \\
\hline II & Glibenclamide $(5 \mathrm{mg} / \mathrm{kg})$ & $91.43 \pm 1.31$ & $81.22 \pm 2.63$ & $67.53 \pm 2.34^{*}$ & $58.12 \pm 2.61^{* *}$ & $54.72 \pm 2.44^{* *}$ & $73.83 \pm 1.42^{* *}$ & $71.63 \pm 2.81^{* *}$ & 21.65 \\
\hline III & Compound-A (250mg $/ \mathrm{kg}$ ) & $89.13 \pm 1.2$ & $87.6 \pm 1.1$ & $87.2 \pm 2.65$ & $86.73 \pm 1.46$ & $86.33 \pm 1.43$ & $86.12 \pm 0.89^{*}$ & $85.32 \pm 1.51$ & 4.27 \\
\hline IV & Compound-A (500mg/kg) & $88.4 \pm 2.43$ & $87.32 \pm 2.16$ & $86.49 \pm 1.87$ & $86.04 \pm 1.67$ & $85.6 \pm 2.69$ & $84.4 \pm 1.43^{* *}$ & $81.32 \pm 2.49^{*}$ & 7.94 \\
\hline $\mathrm{V}$ & Compound-B (250mg/kg) & $92.53 \pm 1.27$ & $91.46 \pm 1.68$ & $89.94 \pm 1.09$ & $87.11 \pm 0.91$ & $86.22 \pm 2.13$ & $84.11 \pm 1.18^{* *}$ & $82.11 \pm 1.89 *$ & 11.22 \\
\hline $\mathrm{VI}$ & Compound-B (500 mg/kg) & $91.18 \pm 0.93$ & $87.30 \pm 0.78$ & $85.49 \pm 2.61$ & $85.21 \pm 1.37$ & $84.33 \pm 2.38^{*}$ & $82.66 \pm 1.21^{* *}$ & $77.42 \pm 2.73^{* *}$ & 15.10 \\
\hline
\end{tabular}

Values are expressed in MEAN \pm S.E.M of six animals. One Way ANOVA followed by Dunnet's t-test (t-value denotes statistica significance at $* p<0.05, * * p<0.01$ respectively, in comparison to group-I)

Table: 2: Effect of Isolated compounds of Tinospora cordifolia on BGL of glucose loaded hyperglycemic rats (oral glucose tolerance test, OGTT)

\begin{tabular}{|c|c|c|c|c|c|c|c|}
\hline Groups & Treatment and Dose & Blood glucos & $\mathrm{l}(\mathrm{mg} / \mathrm{dl})$ & & & & \\
\hline & & $0 \mathrm{~min}$ & $30 \mathrm{~min}$ & $60 \mathrm{~min}$ & $120 \mathrm{~min}$ & $180 \mathrm{~min}$ & $\%$ decrease at end of $3 \mathrm{hr}$ \\
\hline $\mathrm{I}$ & Normal control & $83.75 \pm 0.47$ & $86.50 \pm 0.98$ & $88.50 \pm 0.64$ & $83.50 \pm 0.64$ & $86.50 \pm 0.61$ & - \\
\hline II & Solvent control (tween+ water) & $90.50 \pm 0.64$ & $135.52 \pm 0.64^{* *}$ & $118.83 \pm 0.85^{* *}$ & $98.50 \pm 0.64^{* *}$ & $91.50 \pm 0.44^{* *}$ & 32.48 \\
\hline III & Glibenclamide $(5 \mathrm{mg} / \mathrm{kg})$ & $89.43 \pm 0.40$ & $95.50 \pm 1.04^{* *}$ & $81.53 \pm 0.91^{* *}$ & $72.50 \pm 0.64^{* *}$ & $62.51 \pm 0.72 * *$ & 34.54 \\
\hline IV & Compound-A (250mg/kg) & $83.62 \pm 0.40$ & $98.25 \pm 0.85^{* *}$ & $97.61 \pm 0.91^{* *}$ & $93.50 \pm 0.64^{* *}$ & $89.13 \pm 0.34$ & 9.28 \\
\hline $\mathrm{V}$ & Compound-A (500mg/kg) & $87.50 \pm 0.64$ & $107.31 \pm 1.37^{* *}$ & $102.32 \pm 1.10^{* *}$ & $94.50 \pm 0.64^{*}$ & $91.50 \pm 0.64$ & 15.73 \\
\hline $\mathrm{VI}$ & Compound-B (250mg/kg) & $91.50 \pm 0.64$ & $116.84 \pm 1.10^{* *}$ & $109.83 \pm 0.85^{* *}$ & $102.65 \pm 0.91^{*}$ & $92.50 \pm 0.54^{* *}$ & 20.83 \\
\hline $\mathrm{VII}$ & Compound-B (500 mg/kg) & $82.97 \pm 0.91$ & $128.36 \pm 0.85^{* *}$ & $113.36 \pm 1.10$ & $101.51 \pm 0.64^{* *}$ & $94.51 \pm 0.65 * *$ & 25.89 \\
\hline
\end{tabular}

Values are expressed in MEAN \pm S.E.M of six animals. One Way ANOVA followed by Dunnet's t-test (t-value denotes statistical significance at $* p<0.05, * * p<0.01$ respectively, in comparison to diabetic control group).

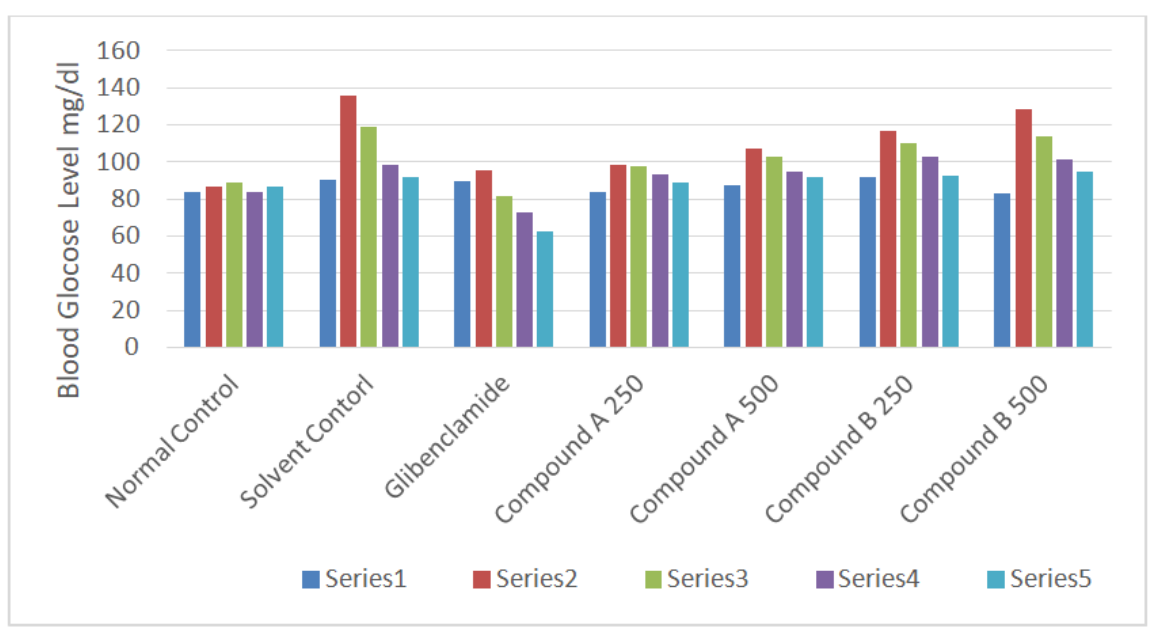

Figure 1: Effect of Isolated compounds of Tinospora cordifolia on oral glucose tolerance in normal rats.

\section{CONCLUSION}

The research work focus on anti-diabetic and hypoglycemic activity of Tinospora cordifolia for their possible to validate their folklore claim followed by chromatographic separation, isolation of presence of phytoconstituent named Compound $\mathrm{A}$ and $\mathrm{B}$ among the most potent fraction of plants. The dose levels of the isolated compounds were selected based on the results of the acute toxicity study and found as $250 \& 500$ $\mathrm{mg} / \mathrm{kg}$ b. w. respectively. Since both Compound A and $B$ showed good activity, hence the investigators think it may be more worth full in terms of its blood glucose lowering ability.

\section{REFERENCES}

1. Aslan M, Erugan F, et al, Hypoglycemic activity and antioxidant potential of some medicinal plants traditionally used intensively for diabetes, Journal of Ethanopharmacology,128,2010,384-389

2. $\mathrm{OECD} / \mathrm{OCDE}$ Guideline for the Testing of Chemicals. Revised Draft Guideline ; Acute Oral Toxicity, 2000, 425.

3. Kulkarni SK, Book of Experimental Pharmacology, Vallabh publisher, $3^{\text {rd }}$ Edition, New Delhi, 2007,128130.

4. Abate N., Chandalia M, The impact of ethnicity on type 2 diabetes, Journal of diabetes and its Complications, 2003, 39-58.

5. Abdel JA, Abdel IA, Al-Hakiem, MH, Hypoglycaemic and antihyperglycaemic effects of Trigonella foenum-graecum leaf in normal and alloxan 
induced diabetic rats. Journal of Ethnopharmacology, 1997,149-155.

6. Turner A, Screening Methods in Pharmacology, Academic Press, New York, London, 2009,227-228.

7. Jarald et al. Indian J Pharmacology 40 (6): 2008,256-260,

8. Ram BL, Singh A, Gade KJ, Fegade SA, Antidiabetic Potential of Tinospora cordifolia (Guduchi) and Momordica charantia (Karela) in Alloxan Induced Rats, International Journal of Pharmacy and Biological Sciences-IJPBSTM (2019) 9 (3): 411-414.
9. Sharma R, Amin H, Prajapati PK, Antidiabetic claims of Tinospora cordifolia (Willd.) Miers: critical appraisal and role in therapy, Asian Pacific Journal of Tropical Biomedicine, 2015; 5(1): 68-78

10. Rajalakshmi M, Eliza J, Edel C, Nirmala A, Daisy P, Anti-diabetic properties of Tinospora cordifolia stem extracts on streptozotocin- induced diabetic rats African Journal of Pharmacy and Pharmacology Vol. 3(5). pp. 171-180, May, 2009. 